\title{
¿Dónde está el error? La epistemología de la verdad en la neurociencia de A. Damasio y la filosofía de R. Descartes
}

\author{
Where is the error? The epistemology of the truth \\ in the neuroscience of A. Damasio and the philosophy \\ of $R$. Descartes
}

MIGUEL GRIJABA UCHE

Cátedra Nacional Hercritia. Facultad de Filosofía. Universidad Nacional a Distancia (uned)

Artículo recibido: 30 de junio de 2017

Solicitud de revisión: 7 de septiembre de 2017

Artículo aceptado: 10 de enero de 2018

Resumen

El presente texto trata de analizar la crítica que Antonio Damasio realiza a René Descartes (el error de Descartes) desde el empleo de una racionalidad neurocientífica. Damasio cae en un neurorreduccionismo para combatir la filosofía cartesiana. La crítica de Damasio al dualismo cartesiano olvida el nivel ontológico y epistemológico para abordar exclusivamente la cuestión antropológica. Este texto propone una defensa de Descartes y un rechazo a un dualismo absoluto a partir de la lectura de Las pasiones del alma.

Palabras clave: Damasio, Descartes, neurobiología y pasiones.

\begin{abstract}
The present text tries to analyze the criticism that Antonio Damasio does to René Descartes (the error of Descartes) from the use of a neuroscientific rationality. Damasio falls into a neuroreductionism to combat Cartesian philosophy. Damasio's critique of Cartesian dualism neglects the ontological and epistemological level to address exclusively the anthropological question. This text proposes a defense of Descartes and a rejection of an absolute dualism based on the reading of Passions of soul.
\end{abstract}

Keywords: Damasio, Descartes, Neurobiologya and passions. 


\section{INTRODUCCIÓN}

Si Descartes hubiera escrito «Siento que pienso, luego existo» (Kushner, 1998: 1) quizás Damasio no hubiera necesitado escribir su libro El error de Descartes. Pero el filósofo de Turena no solo defendió la dicotomía razónsentimiento, sino también sostuvo que los sentidos ofrecían información poco digna de crédito. La razón era sencilla, estos solían acompañarse de cambios corporales tan provisionales y dependientes del contexto como son también el rubor, el sudor o las palpitaciones.

En efecto, Descartes vincula el conocimiento de los sentidos a procesos fisiológicos y no mentales, por tanto, de calado subjetivo, poco apropiados para llegar a la verdad. No forman parte, en consecuencia, del proceso de conocimiento propio de la racionalidad, quedando relegados a un orden inferior, el corporal. El neurocientífico Antonio Damasio considera un verdadero desatino creer que el razonamiento y el juicio moral pueden existir separados del cuerpo, que las operaciones mentales pueden realizarse ajenas a la estructura del organismo. Para Damasio, esta falsa creencia, que achaca en origen a Descartes, ha impregnado el pensamiento y la cultura occidentales durante siglos, retrasando el esfuerzo por comprender la mente en términos biológicos. Precisamente, ese es el reto que se propone a sí mismo: explicar la esencial dependencia de las operaciones mentales y los procesos neuronales.

En el presente trabajo comenzaré por exponer la cuestión de la interdisciplinariedad entre ciencia y filosofía, necesaria para nuestro autor pero que le ha hecho caer en un reduccionismo científico y neuronal para expresar su anticartesianismo teórico. La crítica que Damasio establece al dualismo cartesiano, en donde nuestro autor comete su propio error al ceñirse a un nivel antropológico olvidando la cuestión ontológica sobre el conocimiento, le lleva a cometer la falacia de la objetividad, junto con la naturalización de la mente que realiza Damasio y que le lleva a aislar subjetividad y verdad. Por el contrario, lo que trato de defender en el texto es que la visión cartesiana no olvida lo material, lo corporal a diferencia de lo afirmado por Damasio. El pensar acontece en la confluencia entre el cuerpo y el alma. Por ello, tanto en Descartes como en Damasio, acontece que primero somos, y después pensamos. Para este motivo analizaré varios textos cartesianos como Las meditaciones metafísicas, Las pasiones del alma o Las reglas para la dirección del espíritu, en donde se demuestra esa interdependencia entre cuerpo y mente-alma en Descartes, en contra de lo defendido desde los primeros textos por Damasio. 


\section{LA INTERDISCIPLINARIEDAD BAJO SOSPECHA}

Para Damasio, la cultura occidental arrastra un dualismo de origen cartesiano que nos lleva a percibir lo humano a través de una división que pone, de un lado, el cuerpo, y del otro la mente. Desde esta perspectiva se tiende frecuentemente a identificar la mente como lo distintivamente humano. Por el contrario, nos dice Damasio que «alma y espíritu, con toda su dignidad y escala humanas, son estados complejos y únicos de un organismo» (Damasio, 2001a: 231).

El científico portugués es consciente de que un gran número de filósofos han tratado de salvaguardar, a lo largo de la historia, aquello que consideran el rasgo esencial de todo ser viviente: la unidad de lo heterogéneo. Desde Hipócrates hasta el Renacimiento, asegura, esta ha sido la corriente de pensamiento predominante, corriente que un solo hombre, René Descartes, fue capaz de cambiar.

La discusión acerca de la mente y el cerebro, la naturaleza del alma, hunde sus raíces en la filosofía griega, en la escolástica medieval y en el cartesianismo racionalista de los siglos XVII y XVIII, pero se expresa con inusitado interés en los más recientes estudios científicos neurobiológicos y en la subsiguiente reflexión filosófica acerca de ellos. Así, por ejemplo, Platón, que concibe el cuerpo como la cárcel del alma, piensa que esta última se comunica con lo físico. Pero el estudio y la investigación de las cosas físicas son de importancia secundaria respecto a los asuntos del mundo de las ideas que, siendo más permanente, es más real. La posición de su discípulo Aristóteles es más moderada. Sitúa el pensamiento como producto de la experiencia del cuerpo y, en este sentido, atribuye mayor grado de realidad a los objetos sensibles. En primer lugar, porque la idea que tenemos de todo objeto tiene que tener su origen en la impresión de nuestros sentidos. Y, en segundo lugar, porque es necesario que los mismos fenómenos que producen la sensación, existan independientes de ella. Es decir, acaba otorgando cierta objetividad a los sentidos.

En la actualidad, uno de los temas que más atrae la atención de los investigadores en neurociencia, psicología y filosofía de la mente es precisamente la naturaleza de la conciencia - mente o alma. En el umbral del siglo xxi todavía no sabemos desde la neurobiología cómo pensamos, ni qué es el acto propio de pensar, ni tenemos ninguna teoría que lo explique satisfactoriamente. Damasio, por ejemplo, no lo aborda de modo claro. No hay una respuesta a la pregunta sobre si la mente es una propiedad emergente de la actividad eléctrica y metabólica del cerebro, y, en el caso de que eso 
fuera así, no se conoce tampoco de qué forma la red nerviosa da origen a los fenómenos mentales. Como describe Daniel Dennett, «estamos apenas comenzando a ver los primeros puentes que se están tendiendo sobre el gran abismo de ignorancia entre la psicología y la neuroanatomía» (Dennett, 1995: 3).

Debo destacar que el llamado problema mente-cerebro no es, en modo alguno, el problema alma-cuerpo. El debate contemporáneo acerca de las relaciones entre la mente y el cerebro no tiene nada que ver con aquella otra cuestión acerca de la articulación de alma y cuerpo. La confusión se debe a que el efectivo carácter unitario del ser humano hace que todo lo humano tenga alguna relación. El problema alma-cuerpo versa sobre la posibilidad de que en el cerebro de cada ser humano exista un homúnculo, un hombrecillo, al que llamamos alma, que gobierne el funcionamiento cerebral. Ese es un mito de cuño cartesiano que, a fin de cuentas, no explica nada, puesto que la mente no existe ni opera sin el cuerpo. Por el contrario, el problema mente-cerebro está relacionado con la naturaleza de las correlaciones neurofisiológicas que subyacen al fenómeno mental. Y si bien ambas polémicas comparten puntos de anclaje argumental, su objeto es distinto.

En opinión de Damasio, Descartes es el enemigo que el intelectual moderno ha de combatir. $Y$ ahí es donde yace, a mi juicio, el primer serio desliz de su planteamiento: tratar de rebatir la filosofía cartesiana apelando casi exclusivamente a mediciones y experimentos neuronales. Damasio es bien explícito en este sentido: en sus obras hace constantes alusiones a filósofos de todas las épocas, pero como motivos de inspiración y no tanto como serias fuentes de conocimiento objetivo. Con todo, Damasio se distingue por su defensa de una más sofisticada teoría organicista, que se funda en lo neuronal, pero para luego sublimarla. Pero una atenta lectura de su obra no deja lugar a dudas sobre su opinión acerca del papel hegemónico que tiene la Neurociencia en la búsqueda de los misterios últimos de la existencia humana.

El problema es que Damasio identifica las tesis cientificistas con tesis científicas, es decir, con hipótesis susceptibles de ser sometidas y probadas con métodos experimentales. En otras palabras, los misterios últimos de la humanidad van a ser resueltos gracias a la Neurobiología, según su opinión. Rompiendo una lanza en favor de Damasio, es justo reconocer, en primer lugar, que los límites entre la ciencia experimental y la filosofía siempre han sido difusos. Pero es que, además, la tierra de nadie entre ambas se ha visto significativamente ampliada en una época como la nuestra en la que 
la formalización de las hipótesis científicas ha alcanzado unos niveles de abstracción sin precedentes.

Por supuesto, Damasio no es el primero en alistarse en la cruzada anticartesiana del siglo xx, iniciada por Gilbert Ryle y Ludwig Wittgenstein. Pero probablemente sí que lo sea en utilizar las armas de la Neurociencia para tal fin. El problema, como voy a tratar de mostrar a continuación, es que Damasio desconoce el terreno de batalla, y acaba introduciendo mayores malentendidos en el diálogo entre científicos y filósofos que aquellos que intentaba disolver, como se podrá colegir al final de la lectura de este artículo. Esta es la razón por la que, paradójicamente, este tipo de conductas abiertamente interdisciplinares están promoviendo en la ciencia y en la filosofía, como efecto rebote, actitudes reduccionistas que podríamos definir como defensivas.

Por último, en lo que se refiere al comentario sobre la posible influencia de Descartes en los males de la modernidad, G. Kirkeboen defiende que el dualismo cartesiano no fue el responsable del abismo entre ciencia natural y el dominio del alma, como achaca Damasio, sino que la causa hay que buscarla en el mecanicismo de la nueva ciencia natural de la época, entre cuyos principales promotores estarían Galileo y Kepler (Kirkeboen, 2000: 318). Al contrario, para Descartes, la naturaleza del alma o espíritu es más fácil de conocer que el cuerpo, y eso le impulsa a adentrarse en el estudio de la mente y a escribir su libro Las pasiones del alma. Por tanto, el retraso que le atribuye Damasio en Medicina no es por culpa de Descartes, sino un error grosero de conocimiento en Damasio.

Otra prueba, por último, de que Damasio se equivoca es que, pese a la superación del cartesianismo, el dualismo mente-cerebro no ha sido eliminado ni de la ciencia ni de la filosofía actual. Uno de los neurocientíficos prominentes de este grupo es el premio Nobel John C. Eccles, que defiende un dualismo radical interaccionista entre la mente y el cerebro. Su hipótesis general es que la mente autoconsciente es distinta del cerebro, pero ejerce una función superior de interpretación y control de los procesos neuronales. ${ }^{1}$

1 Eccles resume su tesis dualista en varios principios. En suma, para Eccles, el problema mentecerebro refleja una división real: los procesos de la mente autoconsciente son distintos de los procesos neuronales. Su solución consiste en sostener una interacción entre mente autoconsciente y maquinaria neuronal a través de la corteza asociativa del hemisferio cerebral dominante. 


\section{LA FALACIA DE LA OBJETIVIDAD}

El proyecto asumido por Damasio de querer criticar el dualismo cartesiano desde la Neurociencia es, cuanto menos, valiente. Su opinión es clara y ha levantado numerosas ampollas:

Es interesante, y a la vez paradójico, que muchos científicos cognitivos que creen que pueden investigar la mente sin recurrir a la neurobiología no se considerarían dualistas. Puede que también haya algo de separación cartesiana de mente y cuerpo detrás del pensamiento de aquellos neurocientíficos que insisten en que la mente puede ser explicada exclusivamente en términos de acontecimientos cerebrales, dejando de lado al resto del organismo y al ambiente físico y social que lo rodea (Damasio, 2001a: 230).

De hecho, no pocos colegas de profesión consideraron El error de Descartes un demérito en lo que había sido hasta entonces una brillante carrera científica. En segundo lugar, es admirable su capacidad para captar cuán impregnada está la Neurociencia de sucintos dualismos, así como para entender lo perjudiciales que son algunos de ellos para su buen desarrollo. Fijémonos en el modo concreto en el que Damasio enuncia el error de Descartes:

«Pienso luego existo»... Tomada en sentido literal, la afirmación ilustra precisamente lo contrario de lo que creo que es cierto acerca de los orígenes de la mente y acerca de la relación entre mente y cuerpo. Sugiere que pensar, y la consciencia de pensar, son los sustratos reales del ser.Y puesto que sabemos que Descartes imaginó que el pensar es una actividad muy separada del cuerpo, celebra la separación de la mente, la "cosa pensante» (res cogitans), del cuerpo no pensante, el que tiene extensión y partes mecánicas (res extensa) (Damasio, 2001a: 228).

La formulación que hace Damasio del planteamiento cartesiano da pie a varios equívocos. El más importante tiene por causa el desconocimiento del autor acerca de las intenciones de partida que llevan a Descartes a proponer su máxima sobre la relación entre el conocimiento y el ser, clave para entender la filosofía cartesiana. Porque, en Descartes, por orden de importancia y de dedicación, lo primero es hallar «un conocimiento cierto y evidente» -tarea que pertenece al nivel ontológico. Lo segundo consistiría en construir una filosofía con la que responder, antes que a muchas otras cuestiones, a la pregunta sobre cómo es posible que el ser humano sea capaz de alcanzar conocimientos ciertos - el nivel epistemológico. En este nivel es donde formula la teoría mente-cuerpo. Solo en tercer lugar, se mete Descartes a resolver las paradojas que planean sobre la solución dualista -el nivel antropológico. 
Pero, $e^{\text {es }}$ posible responder a la pregunta por la identidad humana sin atender previamente las cuestiones ontológicas y epistemológicas? Esta afirmación se comprende mejor reformulando la cuestión en los siguientes términos: ¿qué relación guarda el cerebro con la capacidad humana para alcanzar conocimientos verdaderos? Descartes reconoce la circularidad del problema, y trata de resolverla con una respuesta claramente negativa: antes de preocuparnos por el nivel antropológico, hemos de atender la cuestión ontológica. Precisamente, es este el punto de partida que Damasio desconoce, olvido que le lleva a malinterpretar la relación cartesiana entre pensamiento y existencia.

Descartes precisa que desde el «yo pienso» se sigue, clara y distintamente, el «yo existo» en el acto mismo de pensar. Así, el conocimiento que uno tiene de sus propios estados mentales será incorregible, pues la creencia de estar en un cierto estado mental no puede ser errónea porque, si los tenemos, estos son verdaderos. ${ }^{2}$ Pero formar una idea clara y distinta de uno mismo no exige pensar en el cuerpo, y para formar una idea clara y distinta del cuerpo no se tiene que pensar en sí mismo. ${ }^{3}$

De la existencia del conocer, Descartes pasa a las causas del acto cognoscitivo, para lo que ahonda en sus cualidades. Dentro de estas reflexiones cualitativas surgen dos importantes distinciones en Descartes: la que diferencia la sustancia pensante de la sustancia material y la que diferencia el conocimiento objetivo del conocimiento subjetivo. En la primera, Descartes identifica lo esencial al pensar y, en la segunda, los modos de acceso al conocimiento - en primera y en tercera persona, subjetivo frente a objetivo, respectivamente. Nos interesa la segunda distinción para entender otra de las ramificaciones del error cometido por Damasio. El acto cognoscitivo es, para Descartes, previo a la consecución de saberes objetivos, o lo que es lo mismo, no hay enunciados objetivos que no sean los del pensar. Siguiendo este razonamiento, Descartes concluye que el acceso a la primera certeza es un acto de introspección, el despertar a un tipo de realidad

2 Dice Descartes en el Discurso del método, cuarta parte, que es imposible estar pensando y estar equivocado de que pienso. Si estoy dudando, no puedo dudar que estoy dudando. Y del hecho de pensar no podemos estar equivocados de que existimos, puesto que no se puede pensar sin que alguien los realice.

3 Y aun cuando, [...] tengo yo un cuerpo al que estoy estrechamente unido, sin embargo, puesto que por una parte tengo una idea clara y distinta de mí mismo, según la cual soy solo algo que piensa y no extenso, y, por otra parte, tengo una idea distinta del cuerpo, según la cual, este es una cosa extensa, que no piensa, resulta cierto que yo, es decir, mi alma, por la cual soy, es entera y verdaderamente distinta de mi cuerpo, pudiendo ser y existir sin el cuerpo (Descartes, Meditaciones metafísicas, meditación sexta). 
desde la posición privilegiada que tiene el cognoscente respecto de su propio conocimiento. La primera y más segura certeza es, en definitiva, un tipo de conocimiento subjetivo.

El motivo por el que a Damasio le parece paradójica la conclusión acabada de presentar es porque identifica subjetividad con un saber poco fiable, una falsa apreciación que se debe, como se ha mencionado, a no articular los niveles ontológico y epistemológico del pensamiento cartesiano. Apoya esta crítica, en primer lugar, el hecho de que Damasio cae en la confusión de pensar que lo que sí existen son las neuronas en interacción y que, por tanto, su estudio debe ser el punto de partida de toda investigación que pretenda explicar los fenómenos mentales. Existo - tengo neuronas... y un cuerpo-, luego pienso. El oscuro enigma es el pensamiento - la conciencia-, y el mejor modo de resolverlo son las claras certezas objetivas que proporciona la Neurobiología.

Damasio no parece ser consciente de que los conocimientos neurales, aun siendo ciertos, nada dicen de la certeza. Las vivencias psíquicas tienen un papel en la Neurociencia; sin embargo, el rasgo propio del pensar, la intencionalidad del acto cognoscitivo, no acontece. No puede ser de otro modo porque la cualidad intencional - tiene razón Descartes-, solo se puede conocer en la soledad de quien es capaz de abstraer el acto de conocer de lo conocido. Así, una de las más importantes consecuencias del error de Damasio es la reducción del problema cognoscitivo o de la subjetividad - lo que Descartes entiende por mente - al problema de la conciencia, tal como este término es utilizado habitualmente en la Neurociencia contemporánea.

La pregunta cartesiana por la relación cuerpo-mente queda transformada en la pregunta por la relación entre el cuerpo y las experiencias fenoménicas del cuerpo - la sensación de lo que ocurre, utilizando la expresión de Damasio. Es casi inevitable que, partiendo de esta postura, muchos neurobiólogos acaben negando el estatuto ontológico de los eventos conscientes o, al menos, que lleguen a considerarlos meros epifenómenos sin fuerza causal. La razón es la misma que atribuimos a Damasio, la creencia de que lo subjetivo es lo que no es susceptible de objetividad.

Las lecturas de Descartes son interesantes para comprender que lo mental es el más real de todos los fenómenos y además prerrequisito para la objetividad. Pero hay una consecuencia más grave aún que la negación de la primera de las certezas, y de la que científicos como Damasio no son 
conscientes. La reducción de lo mental a lo consciente implica conculcar, en último término, el valor de verdad de los enunciados objetivos. ${ }^{4}$

\section{DESNATURALIZANDO LA MENTE... Y LAS EMOCIONES}

Los éxitos editoriales de Damasio están contribuyendo a desplazar el problema de la verdad lejos del campo de atención de la más formalizada Neurobiología. Pero, ¿hace falta rehabilitar el dualismo cartesiano para salvar la ciencia? No necesariamente, numerosas propuestas filosóficas, desde clásicas - como el hilemorfismo de Aristóteles - hasta modernas - como la fenomenología de Husserl- han puesto de manifiesto la dicotomía subjetividad-objetividad y han propuesto heterogéneas teorías de la identidad de cariz realista. Las lecturas de Husserl, mejor incluso que las de Descartes, ayudan a entender por qué lo que intenta Damasio - esto es, aislar la cuestión de la conciencia de la cuestión de la verdad- conduce a errores categoriales que no hacen sino generar esas paradojas y discusiones absurdas e interminables que paralizan el progreso científico, por lo menos en aquellos investigadores que duermen todavía, utilizando la expresión de Rorty, el sueño metafísico.

Ser capaz de pensar en las apariencias, en términos de apariencias, es ser capaz de pensar en el pensar mismo y de entender, intuitivamente, por qué Descartes separa el pensamiento del mundo físico: las apariencias no son susceptibles de mediciones espaciales. La cuestión es relevante puesto que una mirada libre de prejuicios nos presenta los fenómenos físicos y psíquicos como realidades patentemente distintas. En efecto, es posible detectar los correlatos físicos del pensamiento, pero llegar a la conclusión de que los unos son los otros requiere un discurso que no se encuentra dado en el punto de partida de Damasio.

Damasio confunde el ser fenoménico - por ejemplo, mi tristeza de...con el contenido proposicional, que sí puede ser físico - ...no tener quien me quiera... - o con su causa, que también puede ser física - ...por enfermedad depresiva - . Esta confusión le lleva a identificar la causa del contenido proposicional - el escaso número de receptores de serotonina puede ser la causa de mis pensamientos tristes - con la causa del ser de la rela-

4 Como Richard Rorty ha sabido muy bien argumentar, no es posible mantener una actitud realista fundada en la Neurofisiología. El cerebro no funciona como el espejo de la naturaleza gracias al cual podamos trascender nuestros propios límites biológicos para llegar a saber quiénes somos. La conclusión de Rorty, considerado uno de los padres del materialismo eliminativo, es que la Neurociencia solo puede ofrecer ficciones (Rorty, 1979: 392-393). 
ción - lo que me permite tener conciencia de... En otras palabras, por el acceso privilegiado que tenemos al fenómeno intencional, los conocimientos de lo mental son más fiables que los conocimientos de lo físico.

\section{DESMITIFICANDO A DESCARTES}

Descartes no defiende la escisión cartesiana tal como se enuncia y le atribuyen autores como Antonio Damasio. Él consideró que siendo entidades separadas tienen el mismo significado: yo soy, yo existo como cosa pensante. Y puesto que sabemos que consideraba el pensar como una actividad separada del cuerpo, Descartes lo que celebra es la separación entre la mente, la cosa pensante - res cogitans- del cuerpo no pensante (Damasio, 2003a: 229-230). ${ }^{5}$

De hecho, cuando considera la percepción de otros cuerpos y la influencia de estos en el sujeto, habla de una afectación de este como de un todo compuesto de cuerpo y mente. Pero este combinado cuerpo-mente no parece que posea, para Descartes, ninguna condición ontológica, ya que su relación existente no es una relación de identidad ni tampoco se trata de una relación causal (Lowe, 2000: 40). Lo único que sabe Descartes es que la interacción tiene lugar (Priest, 1994: 20-52). El acto de pensamiento se relaciona con la interacción entre el cuerpo y sus partes mecánicas y la mente -alma.

Descartes fue consciente de la dificultad de aceptar, al mismo tiempo, la distinción sustancial y la unión entre cuerpo y mente, y no teniendo para ello una explicación filosófica convincente, recurrió a una creencia para resolver de modo misterioso la manera en que materia y mente interaccionan. Vivía en un contexto muy influenciado por el contexto filosófico y religioso que ejercieron influencia en él y en sus contemporáneos, lo que determinaba una fuerte tradición de dualismo social, cultural y religiosamente fundamentado. Sobre dicho misterio, dice N. Grimaldi, el espíritu cartesiano está fuertemente vinculado a la disposición y funcionamiento de los órganos del cuerpo (Grimaldi, 1987: 415), lo cual vendría a significar que Descartes, en realidad, tiene la misma postura que la adoptada posteriormente por Damasio: primero somos y, en la medida en que somos,

5 "También me enseña la naturaleza, por medio de esos sentimientos de dolor, hambre, sed, etc., que no estoy metido en mi cuerpo como un piloto en su navío, sino tan estrechamente unido y confundido y mezclado con él, que formo un solo todo con mi cuerpo. Pues si esto no fuera así, no sentiría yo dolor cuando mi cuerpo está herido, puesto que soy solamente una cosa que piensa" (Descartes 1642, Meditaciones metafísicas, meditación sexta). 
pensamos. No en vano, algunos autores han considerado al «pienso, luego existo» como un pleonasmo en donde la palabra luego sería inútil. Para otros podría equipararse con una ecuación química, en donde el luego podría ser reemplazado por el signo $=$. Víctor Hugo considera que Descartes podría haber evitado incluso decir yo soy: ego ergo ego. Se sabe ser antes que se sabe pensar (Hugo, 1959: 234).

G. Kirkeboen tampoco considera que Descartes creyera que el pensamiento fuera una actividad separada del cuerpo. Según él, las opiniones de Damasio han de ser comprendidas como una versión avanzada de las especulaciones de Descartes, ya que este presenta una psicología en la cual el alma inmaterial usa y se relaciona con el cuerpo (Kirkeboen, 2001a: 174). Por ejemplo, Kirkeboen señala que ya en las Reglas para la dirección del espíritu, Descartes plantea que el razonamiento matemático abstracto del intelecto es un proceso cerebral y corporal (Kirkeboen, 2001a: 174).

Para Descartes, algunos procesos psicológicos como memoria, imaginación y percepción sensorial requieren una mente tanto como asiento de la conciencia, como vehículo para la formación de estados mentales, juicio y otras operaciones (Hatfield, 2007: 17). Véase que este aspecto fue mal comprendido por Damasio en la siguiente cita:

\begin{abstract}
El control de la inclinación animal mediante el pensamiento, la razón y la voluntad es lo que nos hizo humanos, según Las pasiones del alma, de Descartes. Estoy de acuerdo con su formulación, con la excepción de que allí donde Descartes especificó un control conseguido mediante un agente no físico yo veo una operación biológica estructurada en el interior del organismo humano y ni un ápice menos compleja, admirable o sublime (Damasio, 2003a: 122).
\end{abstract}

Descartes, tanto en Las pasiones del alma, como en otros escritos, afirma la existencia de estas operaciones en el organismo y que sirven para estructurar y ordenar nuestras inclinaciones, hábitos o pensamientos (Hatfield, 2007:33). Autores de la talla de Merleau-Ponty resaltan las frecuentes aproximaciones simplistas al planteamiento cartesiano. Según él, la cuestión de la unión entre alma y cuerpo en Descartes no es una mera dificultad especulativa, sino que da cuenta de un hecho paradójico: la existencia del cuerpo humano. Lo que se extrae de los textos de Merleau-Ponty es que Descartes se plantea el problema de un cuerpo vivo y mezclado con un alma (Merleau-Ponty, 2000: 17). ${ }^{6}$

6 Merleau-Ponty refuerza la defensa que hace de Descartes con algunas citas. En la carta de agosto de 1641 a Hyperaspistes, Descartes considera que, si lo corpóreo es lo relativo al cuerpo, también será corpórea el alma. En la carta a Elisabeth, del 28 de junio de 1643, explica que se debe concebir 


\section{LAS PASIONES DEL ALMA}

Para Descartes, el término $\operatorname{alma}^{7}$ apenas se distingue de la facultad de pensar o del pensamiento mismo, localizado en la epífisis, bajo el pretexto de que esta glándula está centrada en el cerebro y, por lo tanto, equidistante a todas las radiaciones que vienen de cualquier lugar del cuerpo:

Pienso que cuando Dios una un alma racional a esta máquina, como a continuación expondré, otorgará a esta alma como sede principal el cerebro y hará que su naturaleza sea tal que tenga sensaciones diversas, según las distintas formas en que estén abiertas las entradas de los poros situadas en la superficie del cerebro (Descartes, El tratado del hombre, 50).

A esa alma, Descartes le asocia las pasiones, entendidas estas como verdaderos estados del alma o sentimientos. Pero el origen de las pasiones, en contra de la idea que le atribuye Damasio, se encuentra no solo en el cerebro, sino en todas las partes del cuerpo, en cuanto que sirven para la "producción de sangre y, por ende, de los espíritus ${ }^{8}$. El alma se sumerge en estos estados a través de representaciones que le son dadas normalmente por los movimientos de la glándula: a cada movimiento le corresponde una representación, que induce al alma a caer en un determinado estado. La razón por la que el alma no tiene poder directo sobre las pasiones reside, según Descartes, en que están asociadas a elementos corporales. ${ }^{9}$

De manera similar a como Damasio defiende, también para Descartes la voluntad no puede apaciguar o avivar una pasión de modo inmediato, sino a través de las imágenes de los objetos que van asociados a las pasiones opuestas a las imágenes de las que nos queremos desembarazar. De este modo, se instaura en la filosofía cartesiana una batalla por el control de la glándula, en donde esta puede ser impulsada simultáneamente por el alma

la unión alma y cuerpo a imagen de la unión peso y extensión en la física escolástica. Por este motivo no queda otro remedio que conceder al alma algún tipo de materialidad y, por eso, el alma se concibe como unida al cuerpo (Merleau-Ponty, 2000: 18).

7 La diferencia entre espíritu y alma no es un problema de traducción. Las palabras inglesas mind y soul nos envían a una distinción similar a la comentada, la cual alcanza los límites del campo de investigación de las ciencias neuropsicológicas. Para algunos filósofos, decir alma significa algo más que decir mente. Viene a representar una mente inmortal. Para Aristóteles, alma quiere decir principio de vida, sin presunción de nada espiritual (Kenny, 2000: 48-49).

8 Tras la lectura de los artículos 36, 38 y 39 de Las pasiones del alma tiendo a pensar que Descartes sostenía más bien, y tal como defiende Hatfield, que un único centro cerebral produce, en diferentes individuos, distintos estados mentales (Hatfield, 2007: 15).

9 Bien es cierto que, para Descartes, algunas formas de razonamiento tienen lugar sin la participación del cuerpo. Pero nuestros juicios morales, que dependen de nuestra voluntad, pueden ser ayudados por las pasiones, las cuales están inherentemente causadas por el cuerpo (Hatfield, 2007: 1). 
y por el cuerpo (Descartes, Las pasiones del alma, art. 47). Podemos apreciar en estas afirmaciones que Descartes intuye las correlaciones entre sustancias humorales y fenómenos vasomotores y nerviosos, pudiendo ser tratado como precursor de las ideas que luego desarrollará Claude Bernard (Campan, 1996: 138).

Otra cuestión interesante es que, a pesar de lo que suele creerse, la idea de la glándula pineal como asiento del alma no es exclusiva de Descartes. De hecho, fue defendida previamente por Jean Cousin, en 1641, quien afirmaba que la glándula pineal era el asiento del sentido común (Lokhorst, 2001: 7). Lo que es original en Descartes, y escandalosamente ignorado por Damasio, es su tesis sobre que la mente se ve afectada por la actividad de dicha glándula (Campan, 1996: 138). Por tanto, queda claro que Descartes no defendió un dualismo absoluto, sino una real interdependencia entre ambas sustancias, cuerpo y alma o conciencia, sin la cual no existiría el ser humano.

Damasio critica a Descartes el haberse plegado a la mentalidad de la época, acusación ominosa. Descartes tiene el coraje de presentar el almamente como manifestación del cerebro, y de exponer una relación dual - el cuerpo es el cuerpo, la mente es la mente-, pero aceptando una interdependencia entre estas dos entidades. Pero, además, lejos de generar un retraso en el mundo de la neuropsicología, como también le achaca Damasio, Descartes desarrolla en Las pasiones del alma, una innovadora asociación entre hipótesis de índole fisiopatológica con otras de índole psicopatológica. Este hecho da testimonio de su deseo de establecer uniones entre los procesos mentales y corporales.

En esta misma línea de hipótesis, Hatfield afirma que el funcionamiento del cuerpo humano, en Descartes, siempre conlleva una mente interactuando con el cuerpo, que solo cesa cuando muere este. Aún más, los mecanismos corporales no se limitan a causar estados mentales en una sustancia mental, sino que también funcionan como mecanismos psicológicos que pueden causar comportamientos que no dependen de la mente. ${ }^{10}$

Otra obra que desmiente a Damasio son las Meditaciones metafísicas, en donde Descartes habla de la mezcla entre la mente y el cuerpo. De hecho, es el pionero en el tipo específico de neurobiología de la racionalidad

10 Por lo tanto, desde una visión cartesiana, psicológico — como adjetivo que denota mecanismos que guían comportamientos adaptativos - no es sinónimo de mental — en cuanto que actividad de una mente inmaterial. Por supuesto que hay estados psicológicos que precisan de una mente -e incluso de una interacción mente-cuerpo: percepción sensorial consciente, conocimiento intelectual, emociones intelectuales o actos de la voluntad, entre otros (Hatfield, 2007: 2). 
que el mismo Damasio propone en su libro El error de Descartes (Kirkeboen, 2001b: 196).

Y cuando mi cuerpo necesita comer, beber, tendría yo un simple conocimiento de esta necesidad, sin que de ella me avisaran confusos sentimientos de hambre o sed; pues, en efecto, todos esos sentimientos de hambre, sed, dolor, etc., no son sino ciertos confusos modos de pensar, que proceden y dependen de la íntima unión y especie de mezcla del espíritu con el cuerpo (Descartes, Meditaciones metafísicas, meditación sexta).

De nuevo, ningún escrito posterior de Descartes viene a contradecir esta posición clara y aparentemente opuesta a lo comentado por Damasio sobre Descartes. Para ilustrar este propósito basta leer algunos de los títulos de artículos del libro de Descartes, Las pasiones del alma:

-Art. 122: De los desvanecimientos.

-Art. 128: Del origen de las lágrimas.

-Art. 131: Cómo se llora de tristeza.

-Art. 132: De los gemidos que acompañan a las lágrimas.

-Art. 133: Por qué los niños y los viejos lloran con facilidad.

-Art. 134: Por qué algunos niños palidecen en vez de llorar.

-Art. 135: De los suspiros.

En cada uno de estos artículos Descartes propone una interpretación, asociada a una hipótesis fisiopatológica, del registro cognitivo de cada fenómeno estudiado. Ello testimonia su deseo de establecer lazos entre los procesos del pensamiento y los fenómenos somáticos. En Las pasiones del alma, Descartes da cuenta también de diferentes cuestiones importantes en la Neurociencia actual, incluyendo mecanismos neurofisiológicos descritos en De bomine, como una interesante teoría precursora de la teoría del reflejo, aspectos de psicología introspectiva basados en la experiencia personal o conceptos como emociones - pasiones- intelectuales, así como estudios sobre estados afectivos del hombre, tanto normales como patológicos. ${ }^{11}$ Por último, es precisamente en las Meditaciones metafísicas donde encontramos el principio de babituación cartesiano, en el que Descartes expone una teoría de la racionalidad en la que aparecen integradas las emociones de un modo muy similar a como lo hace Damasio en su hipótesis del marcador somático (LeDoux, 1986: 303; Irons, 1985: 291).

También en Reglas para la dirección del espíritu, Descartes considera al cuerpo y a las emociones como elementos fundamentales en el proceso de

11 El artículo 134 es de sorprendente modernidad, ya que describe de modo muy preciso lo que se denomina, en términos de psicosomática infantil, como espasmo del sollozo. 
razonamiento y racionalidad. Más concretamente, sostiene que nuestros pensamientos (acciones del alma) también causan (o se correlacionan con) cambios de los movimientos de los espíritus animales en el cerebro, y estos cambios pueden activar diferentes pasiones. Hay que reconocerle a Damasio que su idea enfatiza más el hecho de que los marcadores somáticos puedan operar de forma encubierta - sin aparecer a la conciencia- (Damasio, 2003a: 166). Por el contrario, para Descartes, la reacción emocional no posee motivos conscientes como determinantes del comportamiento y la toma de decisiones.

En el mismo orden de cosas, en la regla XII de sus Reglas para la dirección del espíritu, Descartes explica cómo es posible relacionar el comportamiento reflejo, la percepción, la memoria y la cognición con procesos en un cerebro corporal. Descartes asume que el intelecto no tiene acceso directo al exterior, solo trabaja con naturalezas simples que habitan el cerebro de forma causal u ocasional. Por tanto, también podemos decir que para Descartes el cuerpo es una referencia para la mente (Hatfield, 2007: 31). En fin, no parece tener razón Damasio al querer atribuir a Descartes y a sus sucesores el supuesto divorcio moderno entre el cuerpo y el espíritu $y$, en especial, en la medicina occidental. ${ }^{12}$

Incluso podemos llegar a afirmar que la aportación de William James sobre la naturaleza de la emoción y del sentimiento, como un proceso que envuelve al cuerpo, era también la hipótesis de Descartes. Así, este último es claro al considerar las pasiones como una percepción directa de un terreno específico: el del cuerpo. En efecto, como apunta Merleau-Ponty, el cuerpo si capta y siente lo que ocurre fuera de él es por la pasión que lo constituye, donde la pasión es entendida aquí como un tipo de percepción de los sentidos o sensación interna ${ }^{13}$ (Kirkeboen, 2001a: 183). Es decir, son estados mentales que tienen su causa en procesos corporales. Y las denomina pasiones porque la mente es pasiva respecto de un cuerpo activo (Descartes, Las pasiones del alma, arts. 1-2). En este sentido, al leer Las pasiones del alma, encontramos:

Por lo demás, al igual que el curso que siguen los espíritus hacia los nervios del corazón basta para mover la glándula, [...], así también, por el simple hecho de que algunos espíritus van al mismo tiempo hacia los nervios que sirven para mover las piernas para huir,

12 Muy significativos son también los títulos de los artículos del capítulo V de la obra Sobre la búsqueda de la verdad de uno de sus más importantes discípulos, N. Malebranche. Véanse, por ejemplo, los siguientes: Sobre la unión de las ideas del espíritu con el cerebro; Sobre la unión recíproca que existe en las imágenes (huellas) del cerebro; Sobre la memoria.

13 Contrástese con las ideas aparecidas en Descartes, Las pasiones del alma (arts. 27-28). 
provocan otro movimiento en la misma glándula mediante el cual el alma siente y percibe esa huida, la cual puede, de esta forma, ser excitada en el cuerpo únicamente por la disposición de los órganos y sin que el alma participe (Descartes, Las pasiones del alma, art. 38).

Y basta compararla con la exposición de W. James:

Mi teoría [...] es que los cambios corporales que siguen directamente a la percepción de un hecho excitador y el sentimiento de esos mismos cambios que ocurren es una emoción (W. James. 1884/1969: 247).

La diferencia con James estriba en la explicación de cómo dos personas que perciben un objeto de una manera aproximada, pueden tener reacciones emocionales muy diferentes. Incluso una misma persona suele modificar su reacción emocional en diferentes tiempos. Para Descartes, la causa está en que los mismos movimientos de la glándula pueden provocar también diferentes movimientos del cuerpo asociados a las diversas pasiones excitadas en el alma (cfr. Descartes, Las pasiones del alma, art. 39). En efecto, Descartes es el primero en ensayar lo que Damasio pide: un esfuerzo sistemático en comprender la compleja maquinaria que sirve de base a las emociones (Kirkeboen, 2001a: 182). De manera que las pasiones se convierten en esenciales en la preservación del cuerpo y deben ser controladas por el alma (Smith, 1999: 225). Su función es disponer el alma hacia lo que nos sea beneficioso, útil o bueno para el cuerpo (Descartes, Las pasiones del alma, art. 52). Esta es una de las razones por las que el filósofo acepta que la materia produce efectos sobre el espíritu, que lo racional puede ser preso de lo irracional y el espíritu de las pasiones. También la teoría cartesiana es, en último término, un método para alcanzar una vida mejor. Así lo expresa explícitamente en el artículo 148 de Las pasiones del alma.

Pero, de nuevo, a pesar de las múltiples evidencias bibliográficas, Damasio califica de desafortunado el influjo de la filosofía cartesiana en la medicina que tendría continuidad con la metáfora de la mente como programa informático, la explicación de la mente en términos exclusivamente cerebrales o las consecuencias en la medicina tradicional acerca del estudio y tratamiento de la patología psicosomática, entre otros asuntos (Damasio, 2003a: 230-231). En referencia a la crítica de Damasio sobre el abandono del estudio de las enfermedades psicosomáticas en la teoría cartesiana, hay que decir que Descartes había detectado que la mente depende del temperamento y de las disposiciones de los órganos corporales mucho antes 
que nadie. Por ejemplo, así ocurre cuando enfatiza en los efectos de las emociones sobre el cuerpo (Kirkeboen, 2001a: 184).

\begin{abstract}
El principio en el que se apoya todo lo que he escrito, a saber, que la relación entre nuestra alma y nuestro cuerpo es tan profunda que, una vez hemos unido alguna acción corporal con algún pensamiento, ninguno de los dos se presenta sin que el otro se presente también [...]. Es fácil pensar que las extrañas aversiones de algunas personas, que les impiden tolerar el olor de las rosas, o la presencia de un gato, o cosas parecidas, sólo responden a que al comienzo de su vida fueron gravemente afectados por esos objetos (Descartes, Las pasiones del alma, art. 136).
\end{abstract}

El enfoque psicosomático de Descartes se basa en la aceptación de ciertas conexiones entre emociones y movimientos corporales. Lindeboom observa al respecto:

La concepción de la conexión continua de pensamientos espaciales y de fenómenos espaciales del cuerpo [...] representa, junto a la influencia de memorias inconscientes, la base cartesiana de la psicosomática. Podría apenas ser negado que estas nociones esencialmente constituyen, con una considerable extensión, la base del modelo de la moderna psicosomática (Lindeboom, 1979: 91).

En efecto, en la fisiología cartesiana, una terapéutica centrada en el cuerpo será solo una parte de la solución hacia la consecución de la salud, ya que un alma sana es esencial en el mantenimiento y alcance de la supervivencia. Por esto, cuando una pasión nos desordena y nos vuelve tristes, es necesario estar advertidos de todas las imágenes que puede crear en nuestra alma y que nos van a inquietar, e intentar contraponer otras representaciones que terminen expulsando de nuestro interior esas imágenes que no dejan de ser engañosas.

Nuestras pasiones tampoco pueden ser excitadas ni sofocadas por la acción directa de nuestra voluntad, pero pueden serlo indirectamente merced a la representación de las cosas que suelen ir unidas con las pasiones que queremos tener, y que son contrarias a las que queremos rechazar. Así, para excitar en uno mismo la audacia y vencer al miedo, no basta con tener esa voluntad, sino que hay que aplicarse en considerar las razones, los objetos o los ejemplos que convencen de que el peligro no es grande; que siempre hay más seguridad en la defensa que en la huida (Descartes, Las pasiones del alma, art. 45).

Descartes señala que uno de los modos para adquirir una vida mejor es a través del aprendizaje cuidadoso y el control de los mecanismos emocionales. Por tanto, la propuesta cartesiana es dominar las pasiones de tal forma, y manejarlas con tanta habilidad, que los males que causan sean muy soportables, y que de todas ellas se pueda obtener la alegría, como forma 
más deseable de vida. Nótese que, en lo que se refiere a la gestión de las emociones, la propuesta cartesiana es muy parecida a la expresada por Spinoza y, por ende, a la de Damasio.

En síntesis, es difícil entender la mala interpretación que hace Damasio de Descartes. Sospecho que el problema principal se debe a que no ha consultado las fuentes originales. Un indicio de este problema se halla en el último capítulo del libro, donde en parágrafos sucesivos Damasio emplea indistintamente dos términos a los que Descartes no había dado igual significado. En el primer parágrafo, Damasio cita un texto del Discurso del método:

Por ello supe que yo era una sustancia, cuya misma esencia o naturaleza es pensar, y que para su existencia no hay necesidad de ningún lugar, ni dependencia de ninguna cosa material; de manera que este "yo", es decir, el alma por la que soy lo que soy, es completamente distinta del cuerpo, e incluso es más fácil de conocer que éste; e incluso si no existiera el cuerpo, el alma no cesaría de ser lo que es (R. Descartes, El discurso del método, cuarta parte, p. 58)

A continuación, este pasaje es comentado por Damasio de la siguiente forma:

Éste es el error de Descartes: la separación abismal entre el cuerpo y la mente, entre el material del que está hecho el cuerpo, medible, dimensionable, operado mecánicamente, infinitamente divisible, por un lado, y la esencia de la mente, que no se puede medir, no tiene dimensiones, es asimétrica, no divisible (Damasio, 2003a: 230).

\section{CONCLUSIONES}

Damasio aísla la noción de subjetividad (conciencia) de la idea de verdad y presenta una antropología sin ontología. Esta situación le conduce a un monismo fisicalista sui generis. Tal como apunta S. Holm, Damasio pretende explicar el mecanismo por el cual la mente realiza el razonamiento. Pero si dicho mecanismo deja al cuerpo en un lugar secundario, y al cerebro como una posible entidad separada, entonces Damasio no alcanza a refutar lo que él denomina el error de Descartes, es decir, la separación entre cuerpo y alma. La mayor parte de los pensamientos, sensaciones, imágenes, memoria, sentimientos e incluso las pasiones tienen una causa corporal en Descartes y requieren que la mente interactúe con el cerebro, algo que olvida Damasio. Damasio desconoce el campo de batalla que es la metafísica cartesiana y cae en un reduccionismo neuronal porque desco- 
noce realmente la Filosofía además de una naturalización de la mente. Su teoría se encuadra dentro de un monismo materialista de corte cerebrista o neural como explicación del acontecer emocional o de conciencia, tal como se deriva de la lectura de sus libros. El error de Damasio consiste en creer en la Neurobiología como fundamento único de su teoría de la mente. En contraste, sí que hay razones para sospechar que la Neurología no pueda acabar por rellenar el abismo entre lo material y lo espiritual. Damasio no es el único investigador del siglo xx que afirma que Descartes es el enemigo que el intelectual moderno ha de combatir. Sin embargo, la lectura que hace Damasio de Descartes no es correcta: trata de rebatir la filosofía cartesiana apelando casi exclusivamente a la Neurología y acaba introduciendo mayores malentendidos en el diálogo entre científicos y filósofos que aquellos que intentaba disolver.

¿Defendió Descartes un dualismo absoluto? Tal como trato de reflejar, tras una lectura intensa de sus textos, mi respuesta es que no. Para él, existe una real interdependencia entre ambas sustancias, cuerpo y alma o conciencia, sin la cual no existiría el ser humano. El pensamiento nace en la confluencia entre lo material (el cuerpo) y la mente (alma). Siguiendo el mismo hilo conductor, en Las pasiones del alma, Descartes da cuenta también de diferentes cuestiones importantes en la Neurociencia actual, incluyendo mecanismos neurofisiológicos que explican esta interacción mente y cuerpo. Por último, es precisamente en las Meditaciones metafísicas donde encontramos el principio de habituación, en el que Descartes expone una teoría de la racionalidad en la que aparecen integradas las emociones de un modo muy similar a como lo hará posteriormente Damasio con su hipótesis del marcador somático.

Damasio trata de evitar el espejismo homuncular, afirmando que la conciencia - la mente- surge en la interacción entre las representaciones mentales de los objetos y de mi cuerpo en el acto de observar esos objetos. Esta justificación es, a mi parecer, insuficiente. Damasio reconoce que no sabemos con seguridad la manera como el cerebro produce la mente, aceptando un emergentismo débil y un cierto dualismo de punto de vista. Este es otro de los puntos débiles del autor.

La antropología de Damasio se alinea con la de Spinoza y es una interpretación no antropocéntrica de hombre. Sin embargo, también Descartes, como Damasio, utiliza el cuerpo como referencia a la mente, y la relación de las emociones con el cuerpo y la mente. Así, no solo es que Descartes sea menos dualista de lo que Damasio imagina, sino que Damasio es más cartesiano de lo que le gustaría. 


\section{BIBLIOGRAFÍA}

Campan, Louis (1996). A propos de «l'année Descartes». Descartes le physiologist. Urgences, XV, 137-139.

Damasio, Antonio (1990). Individuals with sociopathic behaviour caused by frontal damage fail to respond autonomically to social stimuli. Behav Brain Res, 41, 81-94.

Damasio, Antonio (1994). Descartes' error and the future of human life. Sci Am, 271 (4), 144.

Damasio, Antonio (1998). Investigating the biology of consciousness. Pbilos Trans $R$ Soc Lond B Biol Sci, 353 (1377), 1879-1882.

Damasio, Antonio (1999). How the brain creates the mind. Sci Am, 281 (6), 112-117.

Damasio, Antonio (2000a). Creación cerebral de la mente. Investig Cienc, 46, 66-71.

Damasio, Antonio (2000b). Eighth C.U.Ariens Kappers lecture. The fabric of mind: a neurobiological perspective. Prog Brain Res, 126, 457-467.

Damasio, Antonio (2001a). La sensación de lo que ocurre: cuerpo y emoción en la construcción de la conciencia. Madrid: Debate S.A.

Damasio, Antonio (2001b). Descartes' error revisited. J Hist Neurosci, 10(2), 192-194.

Damasio, Antonio (2001c). In reply to Geir Kirkeboen. J Hist Neurosci, $10(2), 197$.

Damasio, Antonio (2003a). El error de Descartes: La emoción, la razón y el cerebro bumano. Barcelona: Editorial Crítica, SL.

Damasio, Antonio (2003b). Transparent feelings: A reply to Jaak Panksepp and Douglas Watt. Neuropsychoanalysis, 5(2), 215-218.

Damasio, Antonio (2003c). Spinoza's monism and the idea of the body: A repy to Heidi Ravven. Neuropsychoanalysis, 5(2), 229-230.

Damasio, Antonio (2005). En busca de Spinoza. Neurobiología de la emoción y los sentimientos. Barcelona: Harcourt Crítica.

Damasio, Antonio \& Damasio, Hanna (2006). Minding the body. Daedalus, 135 (3), 15-22.

Damasio, Antonio (2007). Neuroscience and Ethics: intersections. Am J Bioetbics, 7(1), 3-7.

Damasio, Antonio (2010). Y el cerebro creó al bombre. Barcelona: Destino.

Damasio, Hanna, Grabowsky, Thomas, Randall, Frank, Galaburda,Albert M. \& Damasio, Antonio (1994). The return of Phineas Gage: clues about the brain from the skull of a famous patient. Science, 264, 1102-1105. 
Descartes, Renné (1637/1981). Discurso del método. Castellón: Los Libros de Plon.

Descartes, Renné (1628/1984). Reglas para la dirección del espíritu. Madrid:Alianza Editorial, SA.

Descartes, Renné (1662/1990). El tratado del bombre. Madrid:Alianza Editorial, SA.

Descartes, Renné (1641/2005a). Meditaciones metafísicas. Madrid: Ed.Tecnos, SA.

Descartes, Renné (1622/2005b). Las pasiones del alma. Madrid: Editorial Edaf, SA.

Grimaldi, Nicholas (1987). Les ambitions médicales de Descartes et sa découverte en 1637 de la principale maladie de l'homme. Hist Sc Méd, XVI, 415-420.

Harris, Edmund (2003). Descartes' error and Spinoza's truth. NASS monograph, 11, 6-23.

Hatfield, George (2007). The Passions of the soul and Descartes's machine psychology. St Hist Pbilos Sc Part A, 38 (1), 1-35.

James, William (1884/1969). What is an emotion? En William James. Collected essays and reviews (244-280). New York: Russell and Russell.

Kenny, Anthony (2000). La metafísica de la mente. Barcelona: Ed. Paidós.

Kirkeboen, George (2001a). Descartes' embodied psychology: Descartes' or Damasio' error? J Hist Neurosci, 10(2),73-191.

Kirkeboen, George (2001b). Sources of Damasio's error.A reply to Damasio. J Hist Neurosci, 10(2), 195-196.

LeDoux, Joseph (1986). The neurobiology of emotion. En LeDoux, Joseph (Ed.). Mind and Brain. Dialogues in Cognitive Neuroscience (301324). Cambridge: Cambridge University Press.

Lindeboom, Gerrit Arie (1979). Descartes and medicine. Amsterdam: Rodopi.

Lowe, Edward Jonathan (2000). Filosofía de la mente. Barcelona: Idea Books, SA.

Merleau-Ponty, Maurice (2000). Fenomenología de la percepción. Barcelona: Ed. Península.

Priest, Stephan (1994). Teorías y filosofías de la mente. Madrid: Cátedra.

Rorty, Richard (1979). Philosophy and the mirror of nature. Princeton: Princeton University Press.

Smith, C.U.M. (1999). $350^{\text {th }}$ anniversary of Les passions de l'ame.J HistNeurosci, 8(3), 221-226. 